\title{
Análisis sobre asimetrías jurídicas entre las normas relativas a los derechos de consumidores, las que regulan el sector energético y las facultades del ente regulador en Nicaragua
}

\author{
Karol Marina Bermúdez Quiroz 38 \\ Universidad Centroamericana UCA Nicaragua \\ kbermudezquiroz@gmail.com
}

Fecha de recibido: octubre 2017 / Fecha de aprobación: diciembre 2017

Actualmente, en materia de consumo Nicaragua posee la Ley No. 842, Ley de Protección de los Derechos de las Personas Consumidoras y Usuarias, publicada en La Gaceta, Diario Oficial, No. I29, del II de julio de 2013 y su reglamento, creados con el objetivo de otorgar seguridad y efectividad en la protección de los derechos de los consumidores. Esta ley reconoce al Instituto Nicaragüense de Energía (INE), facultades exclusivas para regular el sector y las relaciones de consumo que surgen entre sus diferentes agentes, a través de diversas leyes especiales. Ante este panorama resulta oportuno examinar la coherencia y armonía que existe entre ambos cuerpos normativos. En la presente investigación se realiza una introducción a generalidades del sector eléctrico, concernientes a la creación y manejo del mismo. Además, se analizan tópicos tales como: las barreras de acceso al servicio eléctrico, los procedimientos administrativos, la protección de los datos y la privacidad de los consumidores, asuntos que ante la posible inobservancia pueden generar vulneración de los derechos de los consumidores. El objetivo final del presente trabajo es realizar un aporte en beneficio de la sociedad consumidora del servicio público de energía eléctrica, a través de la formulación de soluciones claras que garanticen la armonía de estos dos cuerpos legales.

\section{Palabras Clave}

Derecho de consumidores / energía eléctrica / ente regulador / normativas / asimetría

\section{Abstract}

Currently, the Consumer Nicaragua has Law No. 842, Law on Protection of Consumers and Users, published in La Gaceta, No. 129, of July II, 2013 and its regulations, created with the objective to grant safety and effectiveness in the protection of consumer rights. This law recognizes the Nicaraguan Energy Institute (INE),

38 La autora es Master en Derecho de Empresa con especialización en Asesoría Jurídica por la Universidad Centroamericana, Nicaragua. 
exclusive to regulate the sector and consumer relations arising between agents, through various special laws faculties. Against this background it is appropriate to examine the coherence and harmony between the two regulatory bodies. In this research an introduction is made generalities of, concerning creation and management of the same electrical sector. barriers to access to electricity, administrative procedures, data protection and consumer privacy, matters before the possible failure can lead to violation of consumer rights: In addition, topics such as analyzes. The ultimate goal of this work is to make a contribution for the benefit of the consumer society public electricity service, through the formulation of clear solutions to ensure the harmony of these two legal bodies.

\section{Key Words}

Right consumer / electric power / regulator / laws / asymmetry.

\section{Tabla de contenidos}

Introducción. I. Aspectos generales de la organización y regulación del sector eléctrico en Nicaragua; I.I Antecedentes; I.I.I Crisis energética; I.2 Análisis constitucional del servicio de energía eléctrica; I.3 El sector eléctrico en Nicaragua, organización y regulación; I.3.I Agentes económicos; I.3.2 Agentes consumidores; 1.3.3 Marco institucional del mercado eléctrico de Nicaragua; 1.3.4 Ente regulador regional; I.4 Política centroamericana en materia de energía; 2. La regulación de los derechos de los consumidores a partir de la Ley No. 842, Ley de Protección de los Derechos de las Personas Consumidoras y Usuarias, y su reglamento en relación al sector energético; 2 .I Derecho de los consumidores como derecho humano de tercera generación; 2.2 Derechos generales de los consumidores; 2.3 Las asimetrías jurídicas entre la Ley No. 842, Ley de Protección de los Derechos de las Personas Consumidoras y Usuarias, y su reglamento con las normativas que regulan el sector energético; 2.3. I Barreras de entrada al servicio público de energía eléctrica; 2.3.2 Mecanismos abusivos de cobranza; 2.3.3 Procedimientos de interposición de reclamos y recursos administrativos; 3. Organización y funcionamiento del ente regulador tras la aprobación de la Ley No. 842; Ley de Protección de los Derechos de las Personas Consumidoras y Usuarias y su reglamento; 3 .I Acciones realizadas por el Instituto Nicaragüense de Energía, posterior a la entrada en vigencia de la Ley No. 842, Ley de Protección de las Personas Consumidoras y Usuarias; 3.2 Organización y funcionamiento actual del Instituto Nicaragüense de Energía (INE); 4. Conclusiones, 5. Lista de referencias. 


\section{Introducción}

El acto de consumo, forma parte de la cotidianeidad de la sociedad, ya que a través de éste se pretende satisfacer las necesidades básicas de cada individuo, sobre todo la energía eléctrica que por mandato constitucional es considerada un servicio público básico, y por su naturaleza se encuentra regulado por el Estado. Asimismo, Durban (2008), afirma que;

El suministro de energía, y concretamente la electricidad, constituye un servicio esencial para la comunidad, se trata de un input relevante para la actividad económica en general, que afecta en su base a los costes de los sectores productivos de bienes y servicios; en consecuencia, a la formación de los precios y la inflación, a la renta disponible de los ciudadanos y al nivel de la calidad de vida (p. 43).

El Estado de Nicaragua, mediante la Ley No. 842, Ley de Protección de los Derechos de las Personas Consumidoras y Usuarias, publicada en La Gaceta, Diario Oficial No. 129 del II de julio de 20I3 pretende "promover el marco legal y formular políticas de protección de los consumidores y usuarios, reconociendo como derechos humanos a los derechos de los consumidores y usuarios" (Considerando I, 20 I3); facultando al Ente Regulador del sector energético (Instituto Nicaragüense de Energía, INE), para velar por los derechos de los consumidores, a través de sus normativas y leyes.

Por ello el estudio de las posibles asimetrías jurídicas entre la Ley No. 842 (2013) y las normativas del sector energía, surge de la valoración y la importancia de los derechos de los consumidores como derechos humanos de tercera generación. Sin embargo, los consumidores se encuentran en desventaja, ya que la misma Ley No. 272, Ley de Industria Eléctrica, publicada en La Gaceta, Diario Oficial No. 172 el 10 de septiembre de 2012, establece que las empresas distribuidoras de energía se encuentran en una posición de dominante (art. 8), sobre todo porque en Nicaragua en la zona pacífica y central solamente distribuye energía eléctrica las Empresas Distribuidoras de Energía del Norte y del Sur (DISNORTE-DISSUR), tendencias monopólicas claras, las cuales le impiden al consumidor tener otras opciones de acceso al servicio.

En adición a lo anterior, las leyes fundamentales del sector energético, Ley No. 272 (20I2), Ley No. 554 (20I2) y Ley No. 66I (20I2), y la Ley No. 842 (20I3), fueron creadas en momentos y situaciones históricas distintas, las primeras fueron creadas en un momento de crisis energética con el objeto de sobrellevar y superar la misma, y la otra con un sistema y organización más estable, por tanto es necesario analizar sí existe coherencia entre ambos cuerpos normativos y determinar la existencia de un ejercicio pleno de los derechos de los consumidores en Nicaragua, para la efectiva regulación del Ente Regulador.

Para llevar acabo dicha labor, el tipo de investigación desarrollada es documental argumentativa, partiendo del análisis comparativo entre los cuerpos normativos mencionados. Mediante un enfoque analítico deductivo, a las diferentes fuentes bibliográficas y a la legislación comparada, lo que permitirá determinar si existe una efectiva protección de los derechos de consumidores a partir de la aplicación de las normativas de la materia energética en Nicaragua. 
En el desarrollo de la investigación empezaremos con un acápite relacionado a los antecedentes del sector energía para tener nociones cuando nos referimos a la crisis energética que Nicaragua sufrió, realizaremos un análisis constitucional sobre el servicio público de la energía eléctrica, también describiremos a los actores inmersos en el mercado y todo lo relativo a la organización y regulación del sector eléctrico. Posteriormente, abarcaremos la relación existente entre los cuerpos normativos objeto de estudio, para detectar los núcleos problemáticos existentes lo que permitirá desarrollar conclusiones propicias para establecer recomendaciones que consitituyan un aporte jurídico e incluso de índole social.

Finalmente, es necesario destacar que la Constitución Política de Nicaragua, establece que el acceso al servicio público de energía eléctrica, es inalienable y que le corresponde al Estado garantizarlo, por ello el objetivo fundamental de la suscrita investigadora es poner de manifiesto la importancia que posee el acceso al mismo y la protección que merecen los consumidores, puesto que aunque exista un listado de derechos es necesario un constante estudio y ejercicio efectivo de protección de los mismos, ya que dichos derechos en la práctica se ven desvirtuados por procedimientos engorrosos en algunos casos o por la ausencia total de procedimiento ante la devolución de lo que les pertenece.

\section{Aspectos generales de la organización y regulación del sector eléctrico en Nicaragua}

\section{I.I Antecedentes}

El sector eléctrico en Nicaragua es uno de los más importantes, ya que éste es necesario para el desarrollo de la sociedad y de la industria, es por ello que como punto de partida de esta investigación, abordaremos en orden cronológico su formación y desarrollo. En 1902, según datos de la Empresa Nacional de Transmisión Eléctrica, (ENATREL, s.f.), bajo el gobierno del General José Santos Zelaya, fue creada la primera planta eléctrica en Nicaragua, a la que se nombró "Nicaragua Electric Plant", adquirida posteriormente en 1927, por la compañía norteamericana "Central America Power Corporación", la cual en 194I traspasó su dominio a la entidad de Gobierno "Ferrocarril del Pacífico de Nicaragua", denominando dicha empresa como "Empresa de Luz y Fuerza de Managua". Luego, conforme al Decreto Legislativo No. 102, del 14 de octubre de 1954, dicha empresa se convirtió en ente autónomo con personería jurídica y patrimonio propio con el nombre de "Empresa Nacional de Luz y Fuerza" conocida como ENALUF.

Inmediatamente después de la Revolución Sandinista, el día 23 de julio de 1979, mediante Decreto legislativo publicado en La Gaceta, Diario Oficial No. 2 del 23 de agosto del mismo año, se crea el Instituto Nicaragüense de Energía (INE) el cual asumió las facultades de ENALUF, de generación, transmisión y distribución del suministro energético (ENATREL, s.f.).

Durante el gobierno de la ex Presidente Violeta Barrios, en el año 1994, mediante el Decreto No. 46-94, publicado en La Gaceta, Diario Oficial del I de noviembre de 1994, se crea la Empresa Nicaragüense de Electricidad (ENEL), como una institución del Estado con personería jurídica y patrimonio propio, pasando a asumir la generación, transmisión y distribución de la electricidad; para ese mismo período se convirtió en el ente 
regulador. De esta manera, según información del Instituto Nicaragüense de Energía (INE, s.f.) se separan de éste las funciones netamente empresariales, quedando con las funciones de planificación, formulación de políticas, normalización y regulación de las actividades que realizan las empresas en el sector energía.

El proceso de privatización del sector energético tuvo su inicio en el año 1997 hasta el año 2000, durante ese período el 18 de marzo de 1998, la Asamblea Nacional emitió la Ley No. 272, Ley de la Industria Eléctrica, con la cual segmentó a ENEL. Asimismo, el proceso de reforma integral del sector eléctrico se reforzó con la aprobación de la Ley No. 27I, Ley de Reformas a la Ley Orgánica del Instituto Nicaragüense de Energía, publicada en La Gaceta, Diario Oficial No. 63, del I ${ }^{\circ}$ de abril de 1998, definiéndole al INE las funciones de regulación, supervisión, fiscalización del sector energético y encargado de la aplicación de las políticas energéticas fijadas por la Comisión Nacional de Energía (INE, s.f).

En consecuencia, producto del Acuerdo Presidencial No. II6-99, ENEL fue dividida en siete empresas: cuatro de generación, una de transmisión y dos de distribución; las dos últimas fueron la Empresa Distribuidora de Electricidad del Norte (DISNORTE) y la Empresa Distribuidora de Electricidad del Sur (DISSUR), ambas privatizadas en octubre del 2000 y adquiridas por la empresa transnacional de origen español UNION FENOSA, la cual posteriormente fue adquirida por la empresa Gas Natural, misma que en el año 2013 vendió el 84 por ciento de las acciones que tenía a TSK-Melfosur (Hoy, 20I3, I2 de febrero).

\section{I.I.I. Crisis energética}

Según datos de la evaluación realizada por la Comisión Económica para América Latina y el Caribe (CEPAL, 2003), al final de los años ochenta la empresa estatal encargada del servicio público de energía, presentaba una serie de deficiencias estructurales y coyunturales. Los principales problemas que se presentaban fueron:

i) niveles tarifarios inferiores a los costos marginales de largo plazo, situación que provocaba debilidad financiera de las empresas e insuficiente generación de recursos para enfrentar los gastos de operación, mantenimiento y administración. ii) excesiva interferencia política, utilizando el monopolio eléctrico como herramienta de control social a través de tarifas bajas, inversiones de rentabilidad dudosa y relajamiento de las relaciones con los usuarios. iii) confusión de los papeles empresarial y regulador, y iv) disminución generalizada de la eficiencia de gestión de las empresas estatales, lo que en parte podría ser resultado de los tres problemas anteriores (p. 14).

Aunado a esto, producto de la crisis en el mercado inmobiliario de Estados Unidos de América, la que progresivamente se trasladó al mercado bancario convencional, y posterior en el precio del barril de crudo, -el cual llegó a alcanzar casi los US\$ 150-, Nicaragua se vio ante una crisis energética que provocó fuese decretado Estado de Emergencia Económica en el país, ya que el combustible, en aquel entonces constituía la materia prima de las generadoras eléctricas del país, lo que incrementó el precio de generación por ende el precio en la tarifa de energía de los consumidores finales ( $E I$ Diario de Hoy, 2005). 
En correspondencia a lo anterior, Grigsby (2010) afirma, que en el año 2006, los cortes de energía eléctrica en Nicaragua llegaron a durar hasta ocho horas diarias, afectando toda la producción y la vida cotidiana de toda la población nicaragüense, consecuencia de las fallas técnicas en varias plantas generadoras y la falta de liquidez para comprar energía en el mercado energético centroamericano. Nicaragua logró salir de dicha crisis gracias a la entrada en operaciones de nuevas plantas de generación eléctricas de países como Venezuela, Taiwán y Cuba (El Nuevo Diario, 2007, 15 de julio), que quemaban diesel o búnker, fue la clave para aminorar los apagones masivos. A partir del año 2007, se comenzó a implementar una política energética, la cual consistió en ampliar la oferta de generación de energía con recursos renovables, el cambio de matriz de generación y la electrificación en zonas rurales, según datos del Plan Nacional de Desarrollo Humano, para el año $201 \mathrm{I}$ el $35 \%$ de la producción de energía provino de los recursos renovables (PNDH, 20I2, p. I36); y en la actualidad se encuentra en el proceso de reconvertir la matriz de producción energética del país. Según datos de ProNicaragua (20l4) en el año 2013 Nicaragua generó casi el 50.8 por ciento de su matriz energética con recursos renovables, con varias fuentes de generación de electricidad en el país en geotermia (16.7\%); eólica (14.87\%), hidroeléctrica (12.16\%), y biomasa (7.25\%).

Para el siguiente año su generación de recursos renovables aumentó 52.43 por ciento. El gobierno estimó que para el año 2016, la generación de energía renovable alcanzará los 52.50 por ciento. (La voz del sandinismo, 29 de abril 2016). Asimismo, pretende continuar ampliando la red de distribución nacional, a través del Programa Nacional de Electrificación Sostenible y Energía Renovable (PNSER), con el cual se incrementará el índice de electrificación rural de 72.4 por ciento en $201 \mathrm{I}$ al 85 por ciento para el 2016 (PNDH, 2012, p. I38) ${ }^{39}$.

\section{I.2 Análisis constitucional del servicio de energía eléctrica}

Nuestra Constitución Política (20/4), reconoce el derecho al acceso de la energía eléctrica como un derecho constitucional, al establecer que:

Es obligación del Estado promover, facilitar y regular la prestación de los servicios públicos básicos de energía, comunicación, agua, transportes, infraestructura vial, puertos y aeropuertos a la población, y derecho inalienable de la misma el acceso a ellos. Las inversiones privadas y sus modalidades y las conseciones de explotación a sujetos privados en estas áreas seran reguladas por la ley en cada caso (art. 105).

\footnotetext{
39 A propósito de los recursos renovables útiles para la generación de energía, cabe destacar que esta materia se encuentra regulada por la Ley No. 532, Ley para la promoción de Generación Eléctrica con fuentes Renovables, publicada en La Gaceta, Diario Oficial No. 175 del 13 de septiembre de dos mil doce, la Ley No. 467, Ley de Promoción al Sub-Sector Hidroeléctrico, publicada en La Gaceta, Diario Oficial No. 174 del 12 de septiembre de dos mil doce y la Ley No. 443, Ley de Exploración y Explotación de Recursos Geotérmicos, publicada en La Gaceta, Diario Oficial No. 174 del 12 de septiembre de dos mil doce, las cuales tienen por objetivo promover a través del establecimiento de incentivos, el desarrollo de nuevos proyectos de generación eléctrica con fuentes renovables y proyectos que realicen ampliaciones en la capacidad instalada de generación (Ley No. 532, 2012, art. I).
} 
Tal reconocimiento también lo realiza el periódico mexicano "La Verdad del Sureste", al afirmar que:

El servicio eléctrico no puede ser considerado como una mercancía, debe verse como un derecho humano y social, que debe ser garantizado por el Estado y al cual deben tener acceso todas las personas que habitan en el país (s.f).

El derecho al acceso del servicio eléctrico, constituye un derecho humano de tercera generación, puesto que se encuentra integrado en el grupo número tres, Derechos económicos y sociales, de la Declaración Universal de los Derechos Humanos, y de acuerdo con Castro y Valverde (20I2, p. 3I), "se refieren a las obligaciones mutuas entre el Estado y el individuo, en su dimensión social”. Por ello en Nicaragua, por imperio constitucional el Estado tiene la obligación de facilitar dicho servicio público que además es básico para el desarrollo y bienestar de la sociedad y en contraprestación ésta debe cumplir con el pago del uso de dicho servicio (art. 105).

Adicionado a lo anterior, Damianovich (s.f), afirma que: "La construcción de un sistema internacional de derechos humanos, entre los que se hallan los derechos económicos, sociales y culturales, repercute en el Derecho Público, alcanzando al Derecho Constitucional y al Derecho Administrativo". De esto se puede observar la inclusión que posee el derecho al acceso del servicio público de energía eléctrica en el texto Constitucional y su relevancia y regulación desde el Derecho Administrativo.

Cabe destacar que, al analizar a profundidad y detalle lo establecido por el artículo 105 de nuestra Constitución Política (2014) llama poderosamente la atención que el acceso al servicio eléctrico tiene el carácter de ser un "derecho inalienable". Con lo que podemos decir que dicho artículo cumple con los principios que reconoce la Constitución como propios de la nación nicaragüense, tales como: “...los ideales socialistas y las prácticas solidarias..." (2014, art. 5).

No obstante, Escobar y Argüello (20I5) expresan que el derecho al servicio público de electricidad de los usuarios y la obligación que tiene el Estado de satisfacer éste, se encuentra en contraposición frente al tipo penal de defraudación de fluidos ${ }^{40}$, y la potestad sancionadora del Estado, debido a que el servicio de energía eléctrica es un derecho constitucional para los usuarios, por lo que aplicar una sanción penal por el uso indebido de la energía para uso domiciliario, -cuando es evidente que no se está frente a un acto que ocasione un daño o perjucio a terceros, sino más bien satisface la necesidad de acceder a un servicio básico-, constituye una antítesis de los preceptos constitucionales. Además, en estricto apego a la carta magna, el Estado debería de garantizar el uso, goce y disfrute del servicio eléctrico, ya que para el usuario éste es primordial para su existencia y bienestar. Sin embargo, para dilucidar lo anterior sería

40 En Nicaragua el Código Penal, tipifica el delito como aprovechamiento indebido de fluido eléctrico, agua y telecomunicaciones y es establece literalmente que: "Quien por medio de una conexión ilegal o alterado los sistema de control y mediación, obtenga o utilice para sí o para tercero, los servicios de agua, electricidad, telecomunicaciones u otros servicios públicos, con perjuicios para la empresa suplidora o de otros usuario, por un monto mensual igual o superior a tres salarios mensuales del sector industrial, será sancionado con pena de prisión de uno a tres años y cien a trescientos días de multa”. (art. 236). 
necesario adentrarnos en el estudio de la naturaleza jurídica y exegética de la energía eléctrica, lo cual no es objeto del estudio de esta investigación.

\section{I.3 El sector eléctrico en Nicaragua, organización y regulación}

Según datos oficiales del Ministerio de Energía y Minas (MEM), el mercado eléctrico de Nicaragua, se encuentra constituido por agentes económicos y agentes consumidores, los cuales son:

\section{I.3.I Agentes Económicos}

La Ley No. 272, Ley de Industria Eléctrica, publicada en La Gaceta, Diario Oficial No. 172, del 10 de septiembre de 20I2, define al agente económico, como toda persona natural o jurídica calificada, domiciliada en el país, que desarrolla actividades definidas en las industria eléctrica bajo cualquier régimen de propiedad (art. 8).

$\checkmark$ El Agente Productor, éste vende la generación de energía eléctrica a nivel mayorista, ya sea de producción propia o de terceros. Actualmente, existen diecisiete (I7) agentes productores o empresas, integradas por veintisiete (27) centrales eléctricas - plantas de generación, las cuales conforman el Sistema Interconectado Nacional (SIN) (MEM, 20I3. p._3).

$\checkmark$ El Agente Transmisor, dedicado a la transmisión de energía eléctrica desde las centrales eléctricas de generación hasta los centros de distribución. Según el Acuerdo Presidencial No. I I6-99, la Empresa encargada para la operación y mantenimiento del Sistema Nacional de Transmisión de energía eléctrica, es la empresa estatal ENATREL, a la cual se encuentra adscrita el Centro Nacional de Despacho de Carga (CNDC), el cual es el operador y administrador del Mercado Eléctrico (MEM, 2013. p. 5).

$\checkmark$ El Agente Distribuidor, son las empresas que bajo concesión se dedican a la distribución y comercialización de la energía eléctrica. Estas son de dos tipos, las empresas con grandes áreas geográficas de concesión nacional, como por ejemplo las Empresas Distribuidora del Norte y del Sur (DISNORTE Y DISSUR); y las empresas con sistemas aislados, las cuales pueden ejercer las actividades de generación, distribución y comercialización; por ejemplo Zelaya Luz S.A que distribuye y comercializa energía eléctrica en un área de 8.7 kilometros en poblados de La Unión y Puerto Principe dentro del Municipio de Nueva Guinea, Región Autónoma del Atlántico Sur (RAAS) (MEM, 2013. p. 6).

\section{I.3.2. Agentes Consumidores}

$\checkmark \quad$ El Agente gran consumidor habilitado, son aquellos que requieren gran demanda de energía eléctrica, con un voltaje igual o mayor a I3.8 Kilovoltios (Kv), con una carga concentrada no inferior a I,000 Kilowatts $(\mathrm{kW})$, y pueden realizar compras de energía en el mercado mayorista, es decir, que pueden realizar compras directamente a los generadores. Entre estos, se encuentran empresas tales como: ENACAL, INDEX, CCN, ENSA, AGRICORP y CHDN (MEM, 20I3. p. 8).

$\checkmark \quad$ El Agente gran consumidor, según el Acuerdo INE-03-II-2005, publicado en La Gaceta, Diario Oficial No. 236, del 06 de diciembre de 2005, se entiende que es toda persona natural o jurídica que tenga una carga concentrada mínima de un 
megavatio en un sólo equipo de medición de manera sostenida por un período de I5 minutos en un mes, dicha carga deberá ser registrada durante seis meses.

$\checkmark \quad$ El Agente consumidor, la Ley No. 66I, Ley para la Distribución y el Uso Responsable del Servicio Público de Energía Eléctrica, publicada en La Gaceta, Diario Oficial No. 175 del 13 de septiembre de 20I2, define en materia energética al consumidor como: "persona natural o jurídica a la que una empresa distribuidora provee de energía eléctrica, previa firma de un contrato de servicio eléctrico” (art. 2).

\section{I.3.3. Marco institucional del mercado eléctrico de Nicaragua}

$\checkmark$ Ministerio de Energía y Minas (MEM), fue creado en el artículo 4 de la Ley No. 6I2, Ley de Reformas y Adiciones a la Ley 290, Ley de Organización, Competencia y Procedimientos del Poder Ejecutivo, publicada en La Gaceta, Diario Oficial No. 20 del 29 de enero de 2007; es una institución pública responsable de formular, proponer, coordinar y ejecutar los planes estratégicos y la políticas públicas del sector energético, de recursos geológicos, recursos mineros, recursos geotérmicos, recursos hidroeléctricos e hidrocarburos, con el fin de procurar el desarrollo y óptimo aprovechamiento de los recursos energéticos del país.

Además, asume las facultades de la Dirección General de Recursos Naturales, en especial en materia de recursos minerales, de la Administración de Recursos Geológicos, las cuales eran competencias adscritas al Ministerio de Fomento, Industria y Comercio (MIFIC). Así como las facultades de exploración y explotación de recursos geotérmicos que eran adscritas al INE (MEM, 20I4. p. II) .

$\checkmark \quad$ Instituto Nicaragüense de Energía (INE), el Decreto No. 87, Ley Orgánica del Instituto Nicaragüense de Energía (INE), publicada en La Gaceta, Diario Oficial No. I72 del 10 de septiembre de 2012, establece:

...es un ente descentralizado bajo la rectoría sectorial de la Presidencia de la República, con personalidad jurídica, duración indefinida, patrimonio propio y plena capacidad para adquirir derechos y contraer obligaciones (art. I).

Tiene como funciones principales la regulación, supervisión y fiscalización del sector energía y de la aplicación de las políticas energéticas establecidas por el Miniterio de Energía y Minas (MEM) (art. 3 Ley 272/20I2). Asimismo, debe velar por los derechos de los consumidores; fiscalizar el cumplimiento de normas y criterios técnicos en las actividades energéticas (aprovechamiento, producción, transporte, transformación y distribución); fiscalizar el cumplimiento de normas que promuevan el uso racional y eficiente de la energía eléctrica; velar por el buen funcionamiento y calidad del servicio eléctrico; monitoriar las tarifas de venta de energía de los distribuidores a los consumidores, entre otras funciones establecidas por ley.

$\checkmark$ Centro Nacional de Despacho de Carga (CNDC), el sitio oficial web de ENATREL, www.enatrel.gob.ni, afirma que es la unidad responsable de la administración del mercado eléctrico de Nicaragua, y de la operación del Sistema Interconectado Nacional (SIN). Tiene como objetivo principal programar y realizar el funcionamiento del SIN en forma económica y eficiente, dando prioridad a la calidad y confiabilidad del servicio, así como administrar el Mercado Eléctrico de Nicaragua, en total apego a la Normativa de Operación la cual fue aprobada por el INE. 


\section{I.3.4. Ente regulador regional}

$\checkmark$ Comisión Regional de Interconexión Eléctrica (CRIE), en materia de Derecho Internacional, según su sitio web oficial, www.crie.org.gt, es el ente regulador del mercado regional, posee personalidad jurídica propia y capacidad de derecho público internacional, fue creado por el Tratado Marco, con la finalidad de hacer cumplir el Tratado Marco y sus reglamentos, procurar el desarrollo y consolidación del mercado eléctrico, y promover la competencia entre los agentes del mercado a nivel centroamericano.

\section{I.4 Política Centroamericana en materia de energía}

El Sistema de Integración Centroamericana, en adelante SICA, tiene como objetivo fundamental crear la integración centroamericana, como una región de paz, libertad, democracia y desarrollo, sustentada en el respeto, tutela y promoción de los derechos humanos. (Cancilleria Colombiana, s.f.). Este se encuentra conformado por Secretarías e Instituciones especializadas.

En materia de política energética a nivel centroamericano el órgano encargado de su funcionamiento es la Secretaría de Integración Económica Centroamericana (SIECA), la cual se encuentra directamente relacionada con la Secretaría General del Sistema de Intregración Centroamericano (SICA). El SIECA, según su sitio web oficial, www.sieca.int, facilita la integración económica de Costa Rica, El Salvador, Guatemala, Honduras, Nicaragua y Pananá, todos países miembros del Sistema de la Integración Centroamericana (SICA).

En ese mismo sentido, el sistema de integración centroamericano también cuenta con instituciones especializadas, y en materia energética encontramos la Comisión Regional de Interconexión Eléctrica, en adelante CRIE, (Fundación ETEA, s.f), la cual según su sitio web, www.crie.org,gt, es responsable de regular las relaciones comerciales entre las instituciones públicas y privadas que se conectan al sistema y de fijar las tarifas correspondientes.

Cabe destacar que la CRIE en conjunto con otros organismos regionales conforman el Mercado Eléctrico Regional, (MER), sobre el cual funciona el proyecto del Sistema de Interconexión Eléctrica (SIEPAC), el cual consiste en la ejecución del Primer Sistema de Transmisión Eléctrica Regional que reforzará la red de América Central, dicho proyecto fue denominado "Proyecto Mesoamerica" y pretende interconectar los sistemas eléctricos en América Central, con el objeto de contribuir a la reducción de los costos de energía, mejorar la calidad del servicio, generar mayores niveles de competencia en los mercados nacionales y atraer inversión extranjera al istmo (Quezada, 20I5).

No obstante, el SIEPAC se encuentra listo desde agosto de 2012, sin embargo, los contratos para las importaciones de energía se han visto limitados por la falta de normativa. En lo general, las comercializadoras no se atreven a utilizar el SIEPAC, puesto que existen muchos temas por definir, tales como, las prerrogativas de contratos a largo plazo, los cargos de transmisión. De lo anterior, Quezada (2015) afirma que:

la Superintendencia General de Electricidad y Telecomunicaciones (SIGET) reconocieron que la falta de reglamento limita a que comercalizadores y los 
mismos distribuidores realicen contratos de largo plazo con generadores radicados en Centroamerica.

Respecto a Nicaragua, en el año 2016 se realizaron dos reuniones con los miembros de la Junta Directiva del SIEPAC y los representantes de los países centroamericanos para tratar sobre el avance del proyecto multinacional que permitirá garantizar mejores precios y calidad en el servicio eléctrico. En correspondencia a ello, Mansell citado por Prado (2016), afirma que Nicaragua está realizando proyectos para el cambio de matriz energética, el año 2015 se logró alcanzar el $52 \%$ de fuentes renovables, de los cuales el $5 \%$ fue destinado para intercambio con países de la región. En ese sentido, continuó afirmando que las reuniones sostenidas pretenden dar seguimiento a cada uno de los países miembros, con el objeto de lograr fortalecer la participación de éstos en el Sistema Interconectado Nacional (SIN).

\section{La regulación de los derechos de los consumidores a partir de la Ley No. 842, Ley de Protección de los Derechos de las Personas Consumidoras y Usuarias, y su reglamento en relación al sector energético}

El reconocimiento de los derechos de los consumidores tuvo su origen en Estados Unidos de América en el año 1962, gracias al mensaje que el Presidente John Fitzgerald Kennedy presentó al Congreso sobre la protección de los intereses de los consumidores, en el que destacó la frase "consumidores somos todos". Tal reconocimiento recalcó que éste grupo (consumidores), son el grupo económico más importante, pues representaban las dos terceras partes de los gastos económicos totales, sin embargo, se encuentran en una latente inferioridad frente a los grupos de producción industrial o comercial. (Acedo, 2009, p. 3). Por ello, ante la desigualdad y el aprovechamiento injusto, producto de la posición ventajosa del grupo de producción industrial o comercial, se propició la formación de mecanismos de protección a los consumidores lo que dio origen a la configuración de una nueva rama del Derecho, denominada el Derecho de consumo (Acedo, 2009, p. 5).

En cuanto al concepto de Derecho de consumo, podemos establecer que es el conjunto de leyes de orden social aplicables a los supuestos donde se ven involucrados los consumidores, dentro de una relación de consumo. (Castro y Valverde, 2012, p. 103). De igual forma, Acedo (2009) afirma:

“...se trata de aquella serie de normas jurídicas, tanto de Derecho privado como de Derecho público, además de los criterios jurisprudenciales y científicos, que las interpretan, que tienen la finalidad común de otorgar una protección especial y complementaria a la que ya conseden las disposiciones de general aplicación a una categoría subjetiva acotada, carácter variable en función de los intereses en juego, que se viene denominando consumidor o usuario, pero que siempre ha de reunir la cualidad de ser la parte del contrato que se trate de regular mediante aquellas normas" (p. 103).

En nuestra Constitución Política (2014), se reconoce la protección de los derechos de los consumidores y que establece:

Es deber del Estado garantizar el control de calidad de los bienes y servicios y evitar la especulación y el acaparamiento de los bienes básicos de consumo. El 
Estado garantizará la promoción y la protección de los derechos de los consumidores y usuarios a través de la Ley de la materia (art. 105).

En correspondencia al precepto constitucional, la Ley No. 842, Ley de Protección de los Derechos de las Personas Consumidoras y Usuarias, publicada en La Gaceta, Diario Oficial No. 129, del II de julio de 2013, en adelante Ley No. 842 (20I3), tiene por objeto establecer el marco legal de proteccion de los derechos de los consumidores y usuarios de bienes o servicios, procurando la equidad, certeza y seguridad jurídica. Asimismo, pretende garantizar la adquisión de bienes o servicios de calidad, promover y divulgar la cultura de consumo responsable, respetuoso y la educación sobre los derechos que poseen $(2013$, art. I).

\section{I Derecho de los consumidores como derecho humano de tercera generación}

Una vez dejado claro el concepto del derecho de consumo y los derechos que se protegen, cabe señalar que éstos son reconocidos por la Organización de las Naciones Unidas (ONU) como un derecho humano de tercera generación, así lo afirman Castro y Valverde (20I2), al determinar que:

...los derechos humanos de tercera generación, son derechos subjetivos e intereses legítimos que pertenecen a personas indeterminadas y a diversos grupos sociales distribuidos en varios sectores, que se refieren a ámbitos como el consumo, medio ambiente, patrimonio de la humanidad; $y$ cuyo fundamento es precisamente el principio de solidaridad que garantice la libertad y la igualdad ( $p$. 70).

Sin duda alguna, los derechos de consumidores son parte de los derechos humanos, y resulta sumamente importante reconocer dicha aseveración, pues dicho reconocimiento constituye un mecanismo de protección más amplio con todas las garantías que potencien la protección de los seres humanos, tanto en su manifestación invidual como colectiva.

Por consiguiente, el Estado se ve en la obligación de proteger a los sujetos consumidores, de los agentes económicos que buscan la consecución de mayores ganancias a toda costa; es por ello que su actuar debe estar encaminado en la prevención y protección de sus derechos al momento de la relación de consumo (Castro y Valverde, 20I2, pp. $2|1,2| 2,213)$.

2.2 Derechos generales de los consumidores y la energía eléctrica.

Resulta completamente claro que el Derecho del consumidor es totalmente proteccionista, por consiguiente establece una serie de derechos básicos, los cuales según la legislación española citados por Castro y Valverde (20I5) son:

- La protección contra los riesgos que puedan afectar su salud o seguridad.

- La protección de sus legítimos intereses económicos y sociales; en particular, frente a la inclusión de cláusulas abusivas en los contratos.

- La indemnización de los daños y la reparación de los perjuicios sufridos.

- La información correcta sobre los diferentes bienes o servicios, y la educación y divulgación para facilitar el conocimiento sobre su adecuado uso, consumo o disfrute. 
- La audiencia en consulta, la participación en el procedimiento de elaboración de las disposiciones generales que les afectan directamente y la representación de sus intereses, a través de las asociaciones, agrupaciones, federaciones o confederaciones de consumidores y usuarios legalmente constituidas.

- La protección de sus derechos mediante procedimientos eficaces, en especial ante situaciones de inferioridad, subordinación e indefensión (p. 109).

La legislación nicaragüense, en el art. 6 de la Ley No 842 (2013), establece todos los derechos que tienen las personas consumidoras y usuarias, los cuales para efectos de la presente investigación, seran resumidos a los que tengan relación con la materia de estudio (servicio público eléctrico) y además se señalará a manera de ilustración su abordaje en las normas del sector energético, los cuales son:

- La protección contra los riesgos que puedan afectar su salud, integridad física o su seguridad, al respecto la Ley No. 272, Ley de la Industria Eléctrica (20I2), abarca dicho derecho en su art. 33 pues le obliga a los distribuidores de energía, a construir, instalar, operar y mantener sus instalaciones y los medidores de manera que no constituyan peligro para la seguridad de las personas, de la propiedad y el medio ambiente. De igual forma, la Normativa de Servicio Eléctrico, establece que la empresa distribuidora debe atender las emergencias de manera prioritaria y resolver en el menor tiempo posible (NSE 2.I.I0).

- La protección de sus intereses económicos y sociales, en particular contra las prácticas arbitrarias de cláusulas abusivas en los contratos, para ello el ente regulador, es el encargado de revisar y aprobar los contratos de suministro de energía, los cuales deben asegurar la protección efectiva de los derechos de la partes, en particular de los consumidores, por ser éstos contratos de adhesión (NSE. 3.4.I).

- Derecho a recibir educación sobre consumo responsable y sostenible de bienes y servicios, al respecto Acedo (2009, p. 172) nos dice que la finalidad que persigue "es situar al consumidor en condiciones óptimas de conocimiento para poder realizar la mejor elección", lo que implica que los empresarios se encuentra en la obligación de brindar todo la información necesaria para el disfrute satisfactorio de los bienes y servicios.

- Derecho a recibir información adecuada de sus derechos y mecanismos de protección, para ejercerlos ante los órganos correspondientes, al respecto la Normativa de Servicio Eléctrico (200I), señala que es obligación de la empresa distribuidora de energía, realizar campañas y actividades educativas, para informar a los consumidores, sobre la calidad, seguridad, riesgos de la electricidad y procedimiento de reclamos (NSE, Cap. 2.I).

- Derecho a participar y constituirse en organizaciones en pro de la defensa de sus derechos de consumo, al respecto la Ley No. 842 (20/3), establece que los consumidores pueden organizarse en Asociaciones, las cuales deberan ser legitimadas por la Dirección General de Protección de los Derechos de las Personas Consumidoras y Usuarias (DIPRODEC), con el objeto de promover la protección y defensa de los derechos de los consumidores (art. 95).

- Derecho a la privacidad, es el derecho que tiene el consumidor como individuo a la 
protección de sus datos, si bien es cierto el derecho de consumo, engloba a un conjunto de individuos, sin embargo, Juan Baltazar Durand Carrión citado por Alave (20l3) nos expresa y aclara que:

Definitivamente no podemos equiparar los derechos del consumidor con los derechos personales, pues si bien es cierto recae sobre el individuo su efecto no se limita al mismo si no que dado el interés que tiene para todos los consumidores el efecto recae sobre todo el conjunto.

- Derecho a reclamar ante las instituciones correspondientes sobre el cumplimiento de la Ley No. 842 (2013), en relación a esta derecho la Normativa de Servicio Eléctrico (200I) establece en su capítulo 7, el procedimiento que se debe llevar a cabo, en los reclamos por facturación o daños, reconociendo el derecho que tiene el consumidor a acceder a la justicia. Asimismo, la Ley No. 290, Ley de Organización, Competencia y Procedimientos del Poder Ejecutivo, publicada en La Gaceta No. 35, del 22 de febrero de 2013, establece las instancias a las que se debe acudir ante el Ente Regulador, lo anterior en correspondencia a la Resolución No. 40-02-2006, emitida por el Consejo de Dirección del INE, el veintitrés de febrero del año dos mil seis, y ratificada en Resolución INE No. 53-03-2006 por el mismo Consejo, mediante la cual se unifica el procedimiento de recursos administrativos en materia energética con el establecido en la Ley No. 290 (20I3, art. 14), por ser el Instituto Nicaragüense de Energía (INE); un ente bajo la rectoría del Poder Ejecutivo.

- Derecho a demandar por la vía judicial correspondiente, al respecto la Normativa de Servicio Eléctrico (200I), reconoce el derecho que tienen tanto los consumidores como la Empresa de Distribuibión de energía "a acceder a los órganos administrativos o judiciales correspondientes para la protección de sus derechos y legítimos intereses" (NSE. 7.7.I).

De lo anterior podemos observar la estrecha relación que poseen los derechos generales de los consumidores con los derechos contenidos en las leyes del sector energético ${ }^{41}$, por ello es necesario destacar lo imperioso que es que el Estado tome acciones para la protección de los mismos, sobre todo tomando en cuenta que el servicio eléctrico es muy importante para la sociedad, ya que es necesario para la actividad económica en general, y además influye en la formación de los precios del mercado y la inflación de los bienes y servicios (Durban. 2008, pp. 343, 344).

2.3 Las asimetrías jurídicas entre la Ley No. 842 Ley de Protección de los Derechos de las Personas Consumidoras y Usuarias, y su reglamento con las normativas que regulan el sector energético

\footnotetext{
${ }^{41}$ Los derechos de los consumidores de energía nicaragüense, los encontramos en las diferentes cuerpos normativos que componen esta materia de especial regulación, entre estos tenemos: La Ley No. 272, Ley de la Industria Eléctrica, publicada en La Gaceta, Diario Oficial No. 172 del 10 de septiembre de 2012, la Ley No. 554, Ley de Establidad Energética, publicada en La Gaceta, Diario Oficial No. 175, del 13 de septiembre de 20I2, la Normativa de Servicio Eléctrico emitida por el Consejo de Dirección del Instituto Nicaragüense de Energía, mediante la Resolución No. 006-2000, el día 17 de julio de 200 I.
} 
Continúando con nuestro análisis, toca desarrollar la relación existente entre la Ley No. 842 (2013) y las normativas que regulan el sector energético, para ello es preciso resaltar que los derechos de los consumidores nicaragüenses, se encuentran fundamentados en los siguientes principios básicos; accesibilidad, asociatividad, buena fe, coordinación, igualdad y no discriminación, proconsumidor y correctivo, soberanía de decisión de las personas consumidoras y usuarias, y transparencia en la información y divulgación (Ley 842, 2013, art. 4). El cumplimiento de dichos principios y de la efectiva protección de los derechos de los consumidores corresponde al Estado, es decir a la Administración Pública, que en el caso en particular en materia de energía corresponde al Instituto Nicaragüense de Energía (INE), según las facultades que la Ley No. 842 (2013) y el Decreto 87 (2012), le confieren. Asimismo, afirma Acedo (2009), al expresar que:

La Administración Pública, que tiene la misión de protección de los intereses generales interviene de manera constante en la defensa del consumidor, mediante el ejercicio de las competencias que le son propias...(p. I2).

Por consiguiente, podemos expresar que nos encontramos en el ámbito del Derecho público, puesto que la protección de éstos emana "de los poderes públicos a todo el pueblo" (Acedo, 2009, p. 34), por ello en esta investigación se estudiaran leyes de derecho público.

Siguiendo nuestro análisis, a simple vista se puede observar que las leyes en materia energética pretenden proteger los derechos de los consumidores, pues reconocen el derecho al acceso de energía, a la información, a obtener un servicio de calidad, el acceso a la justicia, entre otros; sin embargo, no podemos dejar a un lado que según la Ley No. 554, Ley de Estabilidad Energética (20I2), Nicaragua se encuentra en crisis energética, por tanto las políticas de gobierno se inclinan en atraer inversión privada para el aumento de la generación de energía, en especial a base de fuentes renovables, para lo cual se implementan una serie de exensiones fiscales e incluso la revocación de multas impuestas a las Empresas DISNORTE-DISSUR, con el objeto "de coadyuvar a la creación del ambiente de armonía y estabilidad que el sector energético necesita para su correcto funcionamiento", así lo establece el artículo 4 de la Ley No. 839 "Ley de Reforma y Adiciones a la Ley No. 272, "Ley de la Indutria Eléctrica", a la Ley No. 554, "Ley de Estabilidad Energética”, de Reformas a la Ley No. 66I, "Ley para la Distribuciòn y el Uso Responsable del Servicio Público de Energía Eléctrica” y la Ley No. 64I, "Código Penal”, publicada en La Gaceta, Diario Oficial No. II3, del I 9 de junio de 2013.

Por ello hemos de realizar un estudio que desarrolle las asimetrías entre las leyes de la materia energética y la Ley No. 842 (20l3), de cara a la efectiva protección de los derechos de los consumidores, los cuales fueron mencionados anteriormente.

\subsection{Barreras de entrada al servicio público de energía eléctrica}

A pesar que por precepto constitucional se establece que es derecho inalienable el acceso al servicio público de energía eléctrica, tanto la Ley No. 272, Ley de la Industria Eléctrica, (20l2) como la Normativa de Servicio Eléctrico (200I), contienen lo que para el objeto de nuestro estudio, denominaremos barreras de entrada al servicio eléctrico, pues para poder gozar de éste bien público, es necesario cumplir con ciertos requisitos, como se podrá observar el art. 37 de la Ley No. 272 (20I2), señala que: 
Cuando los usuarios soliciten un servicio que requiera de la construcción de una nueva obra no prevista en el programa de inversiones del concesionario, los distribuidores podrán requerir de estos, un aporte ya sea en efectivo o en obra, a conveniencia del solicitante. Este aporte devengará intereses y será reembolsable. La Normativa de Servicio Eléctrico definirá la tasa de interés y el plazo de reembolso.

Asimismo, el art. 43 de la misma Ley No. 272 (20I2), establece que:

Los distribuidores tendrán derecho a requerir de todo cliente nuevo un depósito de garantía por el pago del consumo de energía eléctrica, equivalente a un monto máximo de un mes de consumo estimado, el cual será cancelado en un plazo máximo de seis meses. Transcurridos dieciocho meses sin haber incurrido en mora, el concesionario está obligado a regresarle al cliente el depósito con sus respectivos intereses más el deslizamiento cambiario vigente.

Al respecto conviene resaltar que la Normativa de Servicio Eléctrico (200I), reafirma dichos requisitos en sus artículos NSE 3.1.1 ${ }^{42}$ y NSE 3.5. ${ }^{43}$. No obstante, en Nicaragua otro de los servicios públicos básicos reconocidos por la Constitución Política, como es el de acceso a la comunicación, no establece barreras de entrada, tales como cobro de instalación o depósito de garantía, pues por experiencia de la suscrita investigadora, a la hora de realizar contratos de telecomunicaciones (televisión por cable, internet, teléfono), no se requiere un cobro extra para la consecución de éstos.

Por consiguiente, el cuestionamiento que nos planteamos radica en que isí en realidad la energía eléctrica es considerada un bien público puro?. Para dar respuesta a nuestra interrogante, Auping et al, definen a los bienes públicos, como "un bien no exclusivo y no excluyente", puesto que el consumo de éste no debe impedir que otra persona lo adquiera y mucho menos que pague un precio por él. Sin embargo, afirman que la energía eléctrica es un bien mixto, ya que el consumo de este servicio por una persona no impide el consumo del mismo servicio por otra, sin embargo, presenta la característica de ser excluyente puesto que es un bien cobrable (pp. 37, 38).

Con base a lo anteriormente planteado, podríamos decir que el servicio de energía eléctrica, constituye un servicio básico esencial de carácter mixto, puesto que su generación y distribuición se encuentra en manos de empresas privadas y dichas actividades son reguladas por la Administración Pública, por consiguiente es un servicio excluyente, pues para su continúo disfrute exige de un pago por parte del consumidor, y esto se debe a los costos monetarios que requiere su generación y transmisión.

42 NSE 3.I.I. Toda persona natural o jurídica dentro del área de concesión de la Empresa de Distribución tiene el derecho de obtener un servicio eléctrico, previo cumplimiento de los requisitos que para tal efecto fijan la Ley, su Reglamento, esta Normativa y las demás disposiciones aplicables.

${ }^{43}$ NSE 3.5.I. La Empresa de Distribución podrá requerir al solicitante de un nuevo servicio de energía eléctrica un depósito de garantía equivalente a un mes de su consumo estimado basándose en su censo de carga. El solicitante, a su elección, podrá enterar este depósito al contado o en cuotas cuyo plazo no exceda de seis (6) meses. 
Retomando el hecho que el acceso a la energía eléctrica es condicionado, por barreras de entradas, las cuales exigen pago de instalación y depósito de garantía, podemos admitir el hecho que Nicaragua se encuentra en crisis energética para aceptar dichos cobros, de los cuales el segundo se encuentra ligado a la obligación de la empresa distribuidora de energía de devolver el monto de garantía al consumidor. Sin embargo, no podemos obviar que las normativas del sector energético carecen de un procedimiento para la devolución del mismo.

Aunado a lo anterior, en la experiencia profesional de la suscrita investigadora, se ha constatado que a pesar que el depósito de garantía, de manera clara e imperativa, según la Ley No. 272 (20I2) y la Normativa de Servicio Eléctrico (200I), debe ser devuelto a los consumidores, en la práctica la Empresa Distribuidora arbitrariamente somete a éstos a realizar diligencias procedimentales para la devolución de dicha garantía, ya que al cumplirse los dieciocho meses que establece la NSE, no es devuelto de oficio, esto se debe a como anteriomente mencionamos que no existe un cuerpo normativo que establezca el procedimiento que se debe llevar a cabo para la devolución del mismo, dejando en desamparo a los consumidores quienes deben acudir al Ente Regulador para hacer efectivo su derecho.

Otro detalle importante para destacar, es que el Decreto 87 (20I2, art. 2), establece que el Instituto Nicaragüense de Energía, tendrá su domicilio legal en la ciudad de Managua, y posee la facultad de "establecer subcentros regionales, zonales, agencias, representaciones y otras oficinas subsidiarias en cualquier parte del territorio nacional"; sin embargo, en la actualidad existen departamentos y zonas de Nicaragua, que no cuentan con una representación del Ente Regulador, tales como Boaco, Nueva Segovia, Madriz, Rio San Juan y en la Región Autónoma del Atlántico Sur, por consiguiente, podríamos afirmar que existe un acceso limitado a la justicia de parte de los pobladores de dicha zona, pues no pueden dentro de su circunscripción acudir al Ente Regulador del servicio público de energía eléctrica.

En síntesis, el Estado de Nicaragua, debería de revisar los vacíos y desaciertos que poseen las normativas del sector energético, para asegurar un acceso efectivo del servicio público de energía eléctrica, sobre todo en temas de devolución de depósito de garantía, pues el estado actual de su legislación facilita la elución de la responsabilidad que tiene la Empresa de distribución de energía de cumplir con el derecho que tiene el consumidor de obtener el dinero de dicho depósito. Asimismo, es necesario que se tomen medidas que aseguren que los consudimores no tengan limitantes para accesar a la atención del Ente Regulador, pues se debería de abrir en zonas diversas del país agencias de representación que apoyen a los consumidores, sobre todo en aquellos Departamentos del país que no poseen representación alguna.

\subsubsection{Mecanismos abusivos de cobranza}

Otro dato importante, que es merecedor de resaltar en esta investigación es que en el último párrafo del artículo 5 de la Ley No. 554, Ley de Estabilidad Energética, (2012), se encuentra una gran contradicción con la Ley $842,(2013)$ que establece que:

Las personas que siendo clientes de las empresas de distribución y hayan sido comprobados como sustractores ilegales de energía podrán ser publicados en listado público de las distribuidoras, previa certificación del Ente Regulador, 
conforme la normativa dictada (art. 5).

Como se podrá observar, dicha disposición es contraria a uno de los principios de la Ley No. 842 (2013), el cual es el principio de Proconsumidor y correctivo, que establece:

Proconsumidor y correctivo: El Estado, a través de las autoridades y los procesos correspondientes, es responsable de efectuar una real protección de los derechos de las personas usuarias, así como corregir las asimetrías, distorsiones en la información o malas prácticas que vulneren la situación de las personas consumidoras y usuarias frente a las personas proveedoras en los actos de contratación y compra o venta de bienes y servicios. El Estado, está obligado a aplicar la norma más favorable a las personas consumidoras y usuarias, en los casos que haya ambigüedad entre las normas o dudas de interpretación (art. 4. literal 6).

En el sitio web oficial del Instituto Nicaragüense de Energía, no se encuentra un ejemplo de dicho tipo de publicación que contempla la Ley No. 554 (20I2); sin embargo, el simple hecho que exista la disposición anteriormente descrita, podría vulnerar el derecho de privacidad que tienen los consumidores, el cual se encuentra reconocido en el art. 6 numeral I I de la Ley No. 842 (2013) y también podría vulnerar el principio constitucional del "respeto a la dignidad de la persona humana", reconocido en el art. 5 de nuestra Constitución Política.

Aunado a lo anterior, podríamos afirmar que la ley de protección a los consumidores y su reglamento, define dicha acción como mecanismos abusivos de cobranza ${ }^{44}$, ya que a pesar de haberse impuesto una sanción pecuniaria por el uso ilícito de la energía eléctrica, atenta contra la dignidad de la personas, acción que además debe ser certificada por el Ente Regulador, que supone es el órgano administrativo que vela por los derechos de los consumidores.

Relacionado con lo anterior, la Ley No. 621, Ley de Acceso a la Información Pública, publicada en La Gaceta, Diario Oficial No. II 8 del 22 de junio de 2007, obliga a las entidades públicas a difundir, a través de su página Web, las resoluciones que se han dictado para resolver los recursos interpuestos contra los actos administrativos. (2007, art. 20, literal m). Atendiendo lo dispuesto, el Instituto Nicaragüense de Energía, desde la entrada en vigencia de dicha ley ha estado difundiendo las resoluciones de recursos de apelación, de los asuntos relacionados a facturación, daños, energía sustraída, redes, calidad del servicio, entre otros.

44 Mecanismos abusivos de cobranza: para los efectos de la presente ley, son aquellos que utilicen las personas proveedoras para cobrar a las personas consumidoras o usuarias, que afecten su reputación, atente contra la privacidad de su hogar, afecten las actividades laborales o su imagen ante los terceros, o que causen intimidación... (Ley No. 842/2013, art. 5). Asimismo, el reglamento de la Ley 842 (2013), establece: "Para efectos de la aplicación del artículo 10 inciso 21 de la Ley 842 , se consideran mecanismos abusivos de cobranza los siguientes: 3 . Hacer cobros por medio de carteles en el domicilio del deudor o fiador, o hacer cualquier referencia a la deuda a través de medios de comunicación masiva o lugares públicos o privados" (art. 31. inc. 3). 
Sin embargo, no se ha tomado en cuenta el hecho que la Empresa Distribuidora no actualiza los contratos de suministro de servicio eléctrico celebrados con sus clientes ${ }^{45}$, lo que conlleva a la emisión de resoluciones con el nombre de personas que quizás no utilizan el servicio eléctrico con el que se encuentra asociado las resoluciones administrativas productos de un procedimiento completo. Además, no se puede dejar a un lado que la Ley No. 787, Ley de Protección de Datos Personales, publicada en La Gaceta, Diario Oficial No. 61 del 29 de marzo de 2012, en su Considerando V señala la necesidad de equilibrar otras leyes aprobadas por la Asamblea Nacional, en especial a la Ley No. 62I (2007), puesto que se debe garantizar el derecho constitucional a la privacidad personal y familiar. Por tanto, el Ente Regulador se ve en la obligación de cumplir con la ley de manera equilibrada, ejecutando actos que eviten la transgresión de los derechos de los consumidores.

En otras palabras, volviendo al delicado tópico de las energías sustraídas, es muy probable que en el sitio web oficial del INE, se encuentren resoluciones de recursos de apelación, en las cuales se declara responsable de la sustracción ilícita de energía eléctrica a una razón social que posee el nombre de una persona que no ha incurrido en dicha acción, pues incluso ni siquiera habita en el inmueble en que se encuentra instalado el servicio. Lo que podría conllevar al hecho que el nombre de una persona que contrató el suministro de servicio eléctrico, que no habita en el inmueble asociado y que además no sustrajo energía ilegalmente, se encuentra en el ciberespacio asociado a una resolución de energía sustraída.

En una situación hipotética, lo anterior lo podríamos ejemplificar así, supongamos que en el año 2010 la señora María Eugenia Morales Carrión, vendió la propiedad inmueble en la que habitaba al señor Carlos José López Pérez, quien adquirió dicha propiedad con los todos los servicios básicos a nombre de la señora Morales, incluyendo el servicio de suministro de energía eléctrica con la siguiente razón social: MARÍA EUGENIA MORALES CARRIÓN, NIS: 258768I. Posteriormente, en febrero del año 2016, personal técnico de la empresa distribuidora de electricidad en compañía de un inspector del INE, encuentra el equipo de medición manipulado con el objeto de registrar un consumo menor de energía, por tanto proceden a levantar un acta de inspección en la que se reflejan los hechos encontrados y días después se les notifica una factura con un cargo en concepto de energía sustraída. En consecuencia, el señor López, presenta su reclamo con la razón social a nombre de la señora Morales, ante la empresa distribuidora negando los hechos, ante la negativa de DISNORTE, procede a presentar recursos ante el INE hasta agotar la vía administrativa, por consiguiente el Consejo de Dirección del INE ratifica la energía sustraída y en atención al mandato de la Ley No. 62I (2007), procede a publicar en su sitio web oficial la resolución de recurso de apelación, la cual contiene como razón social el nombre de la señora Morales, quien desde hace más de 5 años dejó de ser la propietaria del inmueble, sin embargo su nombre en el ciberespacio se encuentra asociado a una resolución de energía sustraída.

No obstante, ante la obligación de actualización de contratos que la Normativa de

45 NSE. 3.4.4 La Empresa de Distribución deberá actualizar los contratos con los clientes que actualmente cuentan con servicio eléctrico conforme al formato aprobado por el INE, a los que no podrá requerir el pago de cargo alguno o depósito de garantía. 
Servicio Eléctrico, impone a la empresa distribuidora, debemos reconocer que dada la cantidad de consumidores que ésta posee, resultaría difícil que ésta mantenga actualizado cada uno de los contratos de suministro que celebran, y tomando en cuenta la obligación que posee la Administración Pública de difundir las resoluciones que se han dictado para resolver los recursos interpuestos contra los actos administrativos, creemos conveniente, como una medida protectora de los derechos de los consumidores, que al momento de difundir las resoluciones de recurso de apelación, sean solamente asociadas al Número de Identificación de Suministro (NIS) y no a la razón social, por todo lo anteriormente señalado.

\subsubsection{Procedimiento de interposición de reclamos y recursos administrativos}

La Normativa de Servicio Eléctrico (200I, NSE 7.I.I), establece que los procedimientos para la interposición de reclamos, "se regirán por los principios de simplicidad, eficacia, transparencia, igualdad, responsabilidad y gratuidad".

Sin embargo, al analizar dichos procedimientos podemos notar rápidamente que es un procedimiento muy engorroso, pues éste consta de cuatro instancias administrativas, dos ante la empresa distribuidora y otras dos ante el ente regulador, un ejemplo muy claro es en los casos de reclamo por alta facturación de energía eléctrica, en el cual el consumidor dentro de los primeros quince días después de recibida la factura debe presentar su reclamo ante la empresa distribuidora (art. 7.5. I), de ser denegado dicho reclamo, dentro de los siguientes tres días, posteriores a la notificación de la resolución de primera instancia (art. 7.4.3), debe presentar su reclamo en segunda instancia ante el superior de la empresa distribuidora, quien resolverá dentro de los siguientes cinco días.

Posteriomente, ante la negación de la segunda instancia de la empresa distribuidora, de conformidad con el art. 44 de la Ley No. 290, Ley de Procedimientos del Poder Ejecutivo $^{46}$, publicada en La Gaceta, Diario Oficial No. 35, se debe acudir dentro de quince días posteriores a la notificación de la segunda instancia ante el ente regulador a presentar recurso de revisión, si éste es nuevamente denegado, se debe presentar dentro de seis días hábiles posteriores a la notificación de la resolución de revisión, recurso de apelación ante la misma autoridad que emitió la resolución para que ésta la remita al Consejo de Dirección, agotando de esta manera la vía administrativa. Véase flujograma en Anexo.

Como se podrá observar para tener un eficaz acceso a la justicia, se debe de llevar a cabo el procedimiento anteriormente descrito en tiempo y forma, lo que implica que el consumidor deba solicitar permiso para ausentarse de sus labores en cuatro ocasiones, y poder efectuar dichas diligencias por una única factura, lo que se traduce en la disminución de una fuerza laboral y en algunos casos perjuicios económicos en el centro de trabajo del consumidor, para realizar gestiones administrativas engorrosas.

\footnotetext{
46 La Resolución No. 40-02-2006, emitida por el Consejo de Dirección del INE, el veintitrés de febrero del año dos mil seis, y ratificada en Resolución INE No. 53-03-2006 por el mismo Consejo, la cual unifica el procedimiento administrativo, en base a la Ley No. 290, Ley de Organización, Competencia y Procedimientos del Poder Ejecutivo, publicada en La Gaceta, Diario Oficial No. 35 del 13 de febrero de 2013.
} 
Al respecto México presenta un procedimiento administrativo más conciso, Durban (2008. p. 359), nos explica que el proceso de resolución de quejas cuenta con tres tipos de mecanismos, "el primero, denominado conciliación inmediata", esta se realiza vía telefónica o de manera pesonal, además afirma que con "ella se promueve la concialición entre el consumidor y proveedor de manera directa, evitando un proceso lento y complejo". El segundo mecanismo, en caso que no haya conciliación por las partes, tanto el proveedor como el consumidor deberan asistir a una audiencia conciliatoria dentro de la Procuraduría Federal del Consumidor, en adelante PROFECO, con la finalidad de llegar a un acuerdo que permita establecer un compromiso claro para la resolución de la controversia. El tercer mecanismo, es el arbitraje, acá PROFECO actúa como arbitro en el diferendo entre el proveedor y el consumidor, en este mecanismo las partes aportan pruebas que sustenten sus alegatos, posteriomente PROFECO emitirá un laudo con la resolución final, cabe destacar que un dato muy interesante es que afirma Durban que "estas acciones de arbitraje pueden llegar a tener el valor de cosa juzgada".

En resumen, creemos que con base al derecho que tienen los consumidores de acceder a la justicia y al principio de simplificación de los procesos, es necesario que se rediseñe un procedimiento administrativo que no conlleve tantas instancias, y que además éstas procuren ser efectivas para la resolución del desacuerdo desde la primera instancia, sirva, también el modelo mexicano, como un referente alterno en pro de dicha finalidad.

\section{Organización y funcionamiento del ente regulador tras la aprobación de la Ley No. 842, Ley de Protección de los Derechos de las Personas Consumidoras y Usuarias, y su reglamento}

3.I Acciones realizadas por el Instituto Nicaragüense de Energía, posterior a la entrada en vigencia de la Ley No. 842, Ley de Protección de los Derechos de las Personas Consumidoras y Usuarias

Para abordar este acápite, fue necesario realizar entrevistas a funcionarios públicos del INE, para saber con exactitud si hubo algún cambio significativo en las funciones del ente regulador posterior a la entrada en vigencia de la Ley No. 842 (20I3). Referente al tema, el M.A. Centeno, Director de Asunto Jurídicos de INE (comunicación personal, 02 de junio de 2016), explicó que con la entrada en vigencia de la Ley No. 842 y su reglamento, la dirección que tiene a su cargo realizó la debida revisión de estos cuerpos legales con el objetivo de identificar los puntos que poseen relevancia con la función que el INE ha venido realizando desde su creación, los cuales fueron plasmados en un cuadro de análisis.

Asimismo, continúa expresando que se verificó que se cuenta con un equipo de atención al cliente, quienes además de brindar información a los consumidores sobre sus derechos, reciben los recursos administrativos relacionados con reclamos interpuestos ante las empresas distribuidoras de electricidad. También, expresa que se solicitó a la Dirección General de Protección de los Derechos de las Personas Consumidoras y Usuarias del MIFIC, el listado de Asociaciones de Consumidores registradas en la misma, con el objeto de comprobar la legitimación activa para la representación de los intereses de los consumidores, y así dar fiel cumplimiento a lo establecido en el art. 95 de la Ley No. 842 (2013). 
Por su lado, E. Kuan, (comunicación personal, 2 de junio de 2016), manifestó que la entrada en vigencia de la Ley No. 842 (2013), no representó ningún cambio para la Dirección General de Electricidad ni para INE, ya que considera que todos los derechos que la Ley de Protección a las Personas Consumidoras y Usuarias destaca ya se encontraban reconocidos en las leyes del sector energético. No obstante, expresó que el Instituto Nicaragüense de Energía, en atención a las funciones que posee de velar por los derechos de los consumidores, en la actualidad está realizando una campaña de auditoria y verificación de medidores, en distintas zonas de la capital, agregando a dicha campaña revisión de las características de cada servicio eléctrico en dichas zonas de inspección, con el objeto de verificar sí se está realizando tomas de lectura, la correcta aplicación tarifaria, la correcta aplicación de los subsidios, así como respondiendo cualquier duda que presenten los consumidores al momento de la visita.

\subsection{Organización y funcionamiento actual del Instituto Nicaragüense de Energía (INE)}

El Instituto Nicaragüense de Energía (INE), posee su ley creadora la cual es el Decreto No. 87, Ley Orgánica del Instituto Nicaragüense de Energía INE, publicada en La Gaceta, Diario Oficial No. 87, del 10 de septiembre de 2012. En ésta se define que el INE "es un ente descentralizado, bajo la rectoría sectorial de la Presidencia de la República, con personalidad jurídica, duración indefinida, patrimonio propio y plena capacidad para adquirir derechos y contraer obligaciones" (2012, art. I). Asimismo, se establece que goza de autonomía orgánica, financiera y administrativa” (20/2. art. 3). La Dirección del mismo se encuentra a cargo de un Consejo de Dirección, el cual está integrado por tres miembros, de los cuales uno es el Presidente, quien además de ser el representante legal del INE, está a cargo de "la administración, coordinación y supervisión del funcionamiento" (2012, art. 12).

En el sitio web oficial del INE, www.ine.gob.ni, se encuentra el organigrama del mismo, donde se puede observar que consta de:

$\checkmark$ Un Consejo de Dirección

$\checkmark$ Un Secretario Ejecutivo

$\checkmark$ Una Unidad de Relaciones Públicas y Una Unidad de Auditoría Interna

$\checkmark$ Una Oficina de Adquisiciones y Una Oficina de Acceso a la Información Pública

$\checkmark$ Cinco Divisiones Administrativas: División de Asuntos Jurídicos, División de Desarrollo Institucional, División de Control Ambiental, División de Recursos Humanos, División de Administración y Finanzas.

$\checkmark$ Una Dirección General de Electricidad, la que se integra por cinco Direcciones: Dirección de Mercado Mayorista, Dirección de Estudios Económicos y Tarifa, Dirección de Calidad de Servicio, Dirección de Uso Responsable de Energía Eléctrica, Dirección de Atención al Consumidor.

$\checkmark$ Una Dirección General de Hidrocarburos, la cual se encuentra integrada por tres Direcciones: Dirección de Economía y Estadísticas, Dirección de Fiscalización y Dirección Técnica.

El Decreto 87 (2012), establece las funciones que el Instituto Nicaragüense de Energía debe llevar acabo en materia de energía las cuales son:

a) Velar por los derechos de los consumidores; 
b) Fiscalizar el cumplimiento de las normas, criterios, especificaciones, reglamentos y regulaciones técnicas que regirán las actividades de aprovechamiento, producción, transporte, transformación y distribución de la energía eléctrica, de conformidad con las normas de la política energética;

c) Fiscalizar el cumplimiento de las normas y regulaciones tendientes a aprovechar la energía en una forma racional y eficiente;

d) Proponer al Ministerio de Energía y Minas para su aprobación, las normas y regulaciones técnicas sobre la generación, transmisión, distribución y uso de energía eléctrica;

e) Derogado.

f) Velar por el buen funcionamiento del servicio eléctrico, y aplicar los indicadores de calidad, confiabilidad y seguridad;

g) Aprobar, publicar y controlar las tarifas de venta de energía de los distribuidores a los consumidores.

h) Aprobar, publicar y controlar las tarifas de peaje por el uso de las redes de transmisión y distribución eléctrica.

i) Aplicar las sanciones en los casos previstos por las leyes, normas, reglamentos, contratos de concesiones y licencias y demás dispocisiones;

j) Resolver las controversias entre los agentes económicos que participan en el sector energía según lo establecido en la Ley de la Industria Eléctrica;

k) Derogado.

I) Fiscalizar el cumplimiento de las obligaciones y el ejercicio de los derechos de los titulares de licencias y concesiones;

m) Designar interventores en su caso;

n) Derogado

o) Inspeccionar las obras e instalaciones de los titulares de licencias y concesiones para la generación, transmisión y distribución de energía eléctrica;

p) Inspeccionar y controlar los instrumentos de medición instalados por el concesionario y titulares de licencias para el registro de la producción y entrega de la energía eléctrica;

q) Prevenir y adoptar medidas necesarias para impedir prácticas restrictivas de la competencia en el suministro o prestación de los productos y servicios regulados en el subsector eléctrico;

r) Prevenir y adoptar medidas necesarias para impedir prácticas restrictivas de la competencia en el suministro o prestación de la producción y entrega de la energía eléctrica;

s) Derogado

t) Cualquier otra función que le conceda la ley, según sus facultades (art. 4).

Cabe destacar que la Ley 842 (20/3), reconoce la facultad que tiene el Instituto Nicaragüense de Energía, para velar por los derechos de los consumidores, pues establece:

Cualquier persona consumidora o usuaria, residente dentro de la zona de operación de una de las empresas que suministran servicios básicos de agua potable, alcantarillado sanitario, energía eléctrica, alumbrado público, telefonía básica y correo, está en el derecho de exigirle a la empresa prestadora del servicio y al Ente Regulador correspondientes, que se le garantice el servicio respectivo siempre que existan condiciones técnicas y previo cumplimiento de 
los requisitos y regulaciones legales propias del servicio (art. 84).

En adición a lo anterior, en el art. 88 de la Ley 842 (2013), se deja claro que el órgano que velará por la aplicación de la Ley de Protección de los Derechos de las Personas Consumidoras y Usuarias, es el ente regulador no la DIPRODEC, dicho reconocimiento data desde la Sentencia No. 10 del día doce de noviembre de dos mil nueve, emitida por la Sala de lo Constitucional de la Corte Suprema de Justicia, en la cual se establece que la parte final del art. 7.7.2 de la Normativa del Servicio Eléctrico que señala que los clientes pueden recurrir a los procedimientos establecidos en la Ley de Defensa del Consumidor (Ley No. 182/1994), es inconstitucional. Por tanto en la actualidad se dejó claro que:

En el caso de los servicios públicos de telecomunicaciones, energía eléctrica, suministro de agua potable y alcantarillado sanitario, con legislación específica, la aplicación de la presente Ley y su Reglamento corresponden al ente regulador.

Si retomamos ejemplos internacionales acerca del manejo que se hace a este tema, España, por su lado, reconoce en su legislación el derecho de los consumidores al punto de encontrarse plasmado en su Constitución Política, con el objeto de la búsqueda de la justicia social y establece se establece (Castro y Valverde, 20 I2):

En este sentido tenemos que el artículo 51 “....viene a intentar equilibrar el modelo de economía de mercado que, basado en la oferta de bienes de consumo, ha propiciado la posición dominante de las grandes sociedades productores, directa o indirectamente, de dichos bienes con la protección al consumidor frente a la indefensión en que pueden encontrarse en sus relaciones jurídicas con aquellas sociedades" (p. I58).

Al igual que en Nicaragua, existe una ley especial de protección a los derechos de los consumidores, la cual es regulada por el Real Decreto Legislativo $\mathrm{N}^{\circ}$ I, del 16 de noviembre 2007, en el que se aprueba el Texto Refundido de la Ley General para la Defensa de los Consumidores y Usuarios, y otras leyes complementarias, las que contienen los derechos básicos de los consumidores.

Además, cuenta con un organismo para la promoción de objetivos y defensa de los consumidores, el cual es el Instituto Nacional del Consumo. Sin embargo, en matería energética considerando el contenido técnico y económico de la misma, existe un regulador encargado de ver por los derechos de los consumidores, el cual es la Comisión Nacional de Energía, en adelante CNE (Durban , 2008, p. 378).

La CNE fue creada mediante la Ley No. 34/2008, del 7 de octubre, posteriormente en el año 2013, fue integrada a la Comisión Nacional de los Mercados y la Competencia ${ }^{47}$,

47 La Comisión Nacional de Energía, asumió las labores de la Comisición del Mercado de Telecomunicaciones (CMT), la Comisión Nacional de Competencia (CNC), el Comité de Regulación Ferroviaria, la Comisión Nacional del Sector Postal, la Comisión de la Regulación Económica Aeroportuaria (CREA), y el Consejo Estatal de Medios Audiovisuales (CEMA). El periódico el Mundo, afirma que dicha acción de unificación responde a las medidas de ahorro de costes de Administración unificando los distintos supervisores en un único regulador. (El Mundo, 2013, 5 de septiembre). 
la cual se encuentra diseñada como un modelo de regulación independiente, único, transparente, y sometido al control del parlamento, para que su ejercicio sea efectivo, se encuentra estructurado según su sitio web oficial (www.cnmc.es) de la siguiente manera:

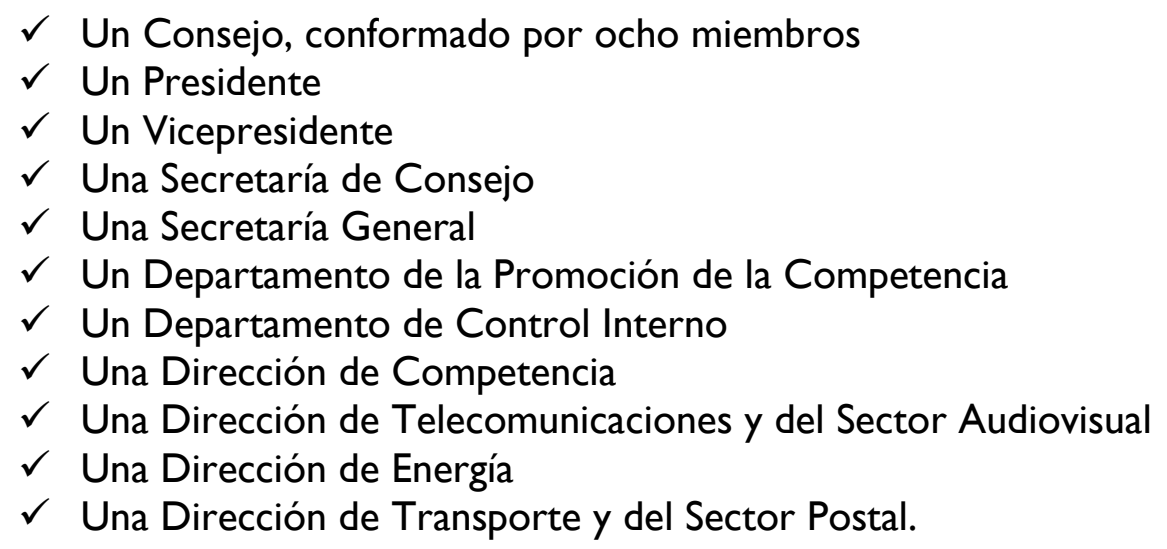

Otro ejemplo muy claro de regulación es Argentina que también posee una Ley especial en materia de derechos de los consumidores, la cual es la Ley No. 24.240 y entró en vigencia el I de octubre de 1993, posteriormente fue reglamentada por los Decretos I798/94 y 56I/99, y modificada, parcialmente, por la Ley $N^{\circ} 26.36 \mathrm{I}$, del siete de abril de 2008, las reformas efectuadas pusieron en armonía la legislación argentina con las nociones internacionales sobre el derecho del consumidor (Castro y Valverde, 20I2. p. 142).

Con relación al servicio público de energía eléctrica, en Argentina el mercado eléctrico fue estructurado siguiendo con las bases y normas que se desarrollaron durante el proceso de organización del sector eléctrico y la transferencia de las empresas al sector privado (Fandiño, 2008, p. 44). Por consiguiente se crearon instituciones con roles respectivos que rigen el mercado eléctrico y la protección de los derechos de los consumidores, las cuales son:

$\checkmark$ La Secretaría de Energía, tiene como finalidad manejar la política energética, dar seguimiento al mercado eléctrico (oferta y demanda) y además tiene la facultad de fijar los criterios del despacho del mercado mayorista y la fijación de los precios de la potencia (2008, p. 46). Cabe destacar que según el organigrama del Ministerio de Energía y Minas de Argentina (www.minem.gob.ar), la Secretaría de Energía se encuentra bajo su subordinación, y ésta a su vez posee cuatro subsecretarías bajo su rectoría las cuales son: Subsecretaría de Energía Renovables, Subsecretaría de Energía Hidroeléctrica, Subsecretaría de Energía Nuclear y Subsecretaría de Energía Térmica, Transporte y Distribución de Energía Eléctrica.

$\checkmark$ La Compañía Administradora del Mercado Eléctrico Mayorista (CAMMESA), Fandiño afirma que a ésta se le asignaron funciones de coordinación y despacho del sistema, la administración comercial del mercado y la publicidad de las transacciones económicas tanto mayorista como administradora del sistema. Es importante señalar que CAMMESA, curiosamente, se encuentra constituida 
como una Sociedad Anónima sin fines de lucro (2008, p. 47).

$\checkmark$ El Consejo Federal de la Energía Eléctrica, Fariña nos dice que es el organismo consultivo de la Secretaría de Energía (2008, p. 47). No obstante, su sitio web oficial, www.cfee.gov.ar, destaca que fue creado en el año 1960, mediante la Ley No. 15.336 y el Decreto Reglamentario No. 2073, y que posee una doble responsabilidad, la primera como administrador de los fondos destinados únicamente al sector eléctrico y la segunda responsabilidad como asesor del Poder Ejecutivo Nacional y de los Gobiernos Provinciales, en temas relacionados a "los servicios públicos o privados de energía, las prioridades en la ejecución de estudios y obras, concesiones y autorizaciones, precios y tarifas del sector eléctrico". También, aconsejar las modificaciones que requiera la legislación en materia de industria eléctrica.

$\checkmark$ El Ente Nacional Regulador de la Electricidad, fue creado por Ley Marco y se encuentra integrado por un cuerpo colegiado de cinco miembros, elegidos por concurso y aprobación legislativa. Según su página web, www.enre.gov.ar, "es un organismo autárquico encargado de regular la actividad eléctrica y de controlar que las empresas del sector cumplan con las obligaciones establecidas en el marco regulatorio". Tiene como objetivos principales:

- Proteger adecuadamente los derechos de los usuarios.

- Promover la competitividad en la producción y alentar inversiones que garanticen el suministro a largo plazo.

- Promover el libre acceso, la no discriminación y el uso generalizado de los servicios de transporte y distribución.

- Regular las actividades del transporte y distribución asegurando tarifas justas y razonables.

- Incentivar y asegurar la eficiencia de la oferta y la demanda por medio de tarifas apropiadas.

- Alentar la realización de inversiones privadas en producción, transporte y distribución, asegurando la competitividad de los mercados donde sea posible.

Con relación a nuestro estudio, es necesario destacar las funciones que tiene el ENRE, y según su sitio web, actualmente éste se encuentra conformado por dos unidades y un departamento vinculados a la atención de los consumidores o usuarios del sector eléctrico, las cuales son:

- La Unidad Operativa de Atención al Público (UOAP), encargada de organizar, coordinar y supervisar la atención a los usuarios, y la tramitación de las denuncias y reclamos recibidos ya sean personalmente, por telefóno, fax o correo.

- La División de Inspección Técnica (DIT), encargada de desarrollar, organizar e instrumentar el sistema de inspecciones vinculados o fallas o cortes del suministro eléctrico. Incluso actua como un servicio de guardia disponible las 24 horas, en casos que se amerite acudir al lugar de los hechos, ante situaciones que puedan vulnerar la seguridad pública.

- El Departamento de Atención a Usuarios (DAU), encargado de tramitar y 
resolver reclamos técnico-comerciales, de falta de suministro reinterativo, de daños a artefactos e instalaciones eléctricas. Asimismo, se encarga de tramitar y administrar los recursos que pueda surgir, formular cargos, aplicar sanciones y penalidades a las empresas, así como también notificar resoluciones a las distribuidoras y usuarios del servicio eléctrico.

Nicaragua ha venido desarrollando un papel similar a los países de España y Argentina, puesto que determinar un órgano especializado que vele por el funcionamiento del mercado eléctrico, ya sea por razones técnicas, financieras o económicas ha resultado el modelo ideal para lberoamérica. Sin embargo, se debe reforzar la "búsqueda de la justicia social" a como considera España es el objeto principal de los derechos de los consumidores, por ello esperamos que la presente investigación constituya un aporte doctrinario a la consecución de la misma. De igual forma, Nicaragua podría aprovechar el ejemplo del sistema argentino en materia de regulación del servicio de energía pública, puesto que como se puede observar su ente regulador se secuentra conformado por tres subsectores, de los cuales uno es el encargado de la atención a los usuarios del servicio, esto debido a la gran importancia que poseen los derechos de los consumidores.

Algo similar ocurre en Nicaragua en materia de finanzas, el cual constituye otro de los mercados regulados y que cuenta con leyes y órganos especializados para la protección de los derechos de los consumidores, y en ese sentido, la Superintencia de Bancos y Otras Instituciones Financieras (Siboif), por mandato de ley creó la Dirección de Atención a las Personas Usuarias del Servicios Financieros "cuya función principal es recibir consultas, reclamos y denuncias presentadas por los consumidores" (Escobar, 20I5, 24 de abril).

En atención a lo anterior, cabe destacar que el último párrafo de la art. 3 del Decreto 87 (20I2) establece: "Para el exacto cumplimiento de sus funciones, el Instituto gozará de autonomía orgánica, financiera y administrativa". Por consiguiente, considerando que el derecho de consumo es un derecho humano de tercera generación, reconocido por la Organización de Naciones Unidas (ONU), es propicio que el ente regulador nicaragüense, en atención de su función de velar por los derechos de los consumidores (Decreto 87, 20I2. art. 4), cree una Dirección General de Atención a las Personas Consumidoras y Usuarias independiente a la actual Dirección General de Electricidad del INE, la cual se encargue únicamente de asuntos relevantes a la protección de los derechos de los consumidores del sector, tomando como referencia el modelo nacional en materia financiera y el modelo internacional de Argentina.

\section{Conclusiones}

Del estudio sistemático comparativo realizado entre la Ley No. 842, Ley de Protección de los Derechos de las Personas Consumidoras y Usuarios, y su reglamento con las normativas que regulan el sector energético, podemos concluir que:

I. Los consumidores a pesar de representar las dos terceras partes de los gastos económicos totales del sector, se encuentran en una posición de inferioridad en la relación de consumo, de cara al grupo de producción industrial o comercial, es por ello que es importante que el Estado tome acciones para hacer efectiva la protección de los derechos de las personas consumidoras y usuarias sobre todo 
en relación al servicio público de energía eléctrica, que a como concluimos es un bien público mixto, pues es un bien no exclusivo pero cobrable.

2. La Normativa de Servicio Eléctrico (200I) posee un gran vacío, el cual tiene relación con la devolución del depósito de garantía que pagan los consumidores para poder acceder al servicio eléctrico de energía; por tanto, es necesario que el Instituto Nicaragüense de Energía (INE), en atención a sus funciones, proponga un procedimiento expedito para la devolución del mismo, en aquellos casos que las empresas distribuidoras no lo puedan devolver de manera oficiosa.

3. Es indispensable la abolición del limitado acceso que poseen los consumidores en ciertas zonas del país, pues ante la ausencia de agencias o sucursales en representación del ente regulador, se podría limitar el acceso a la justicia y a su derecho de la información, por ello es importante promover la formación de nuevos puestos de atención a los consumidores y la mejora de los canales de comunicación, ya sea recibiendo quejas, reclamos, consultas vía telefónica, correo, fax o correo electrónico, con el objeto de asegurar un eficaz acceso a la justicia e información.

4. Respecto al procedimiento de interposición de reclamos y recursos administrativos, estamos claros que el actual procedimiento no cumple con el principio de simplicidad, ya que es un trámite engorroso que conlleva cuatro instancias, por ello es necesario que se rediseñe dicho procedimiento, ya sea disminuyendo la cantidad de instancias (una ante la empresa distribuidora y una ante el ente regulador) o innovando en su totalidad con un procedimiento oral que agilice la resolución de las controversias, tales como la conciliación y/o el arbitraje, tal como se emplea en la legislación mexicana sobre la materia.

5. En relación a los aspectos de publicidad de las resoluciones emitidas por el ente regulador, referente a la razón social de aquellos consumidores que ya no son los usuarios de los servicios eléctricos y que se ven relacionados con procedimientos administrativos, ya sea por reclamos de alta facturación 0 sustracción de energía eléctrica, estamos concientes que el Instituto Nicaragüense de Energía por imperativo de la Ley No. 62I, Ley de Acceso a la Información Pública, publicada en La Gaceta, Diario Oficial No. II 8 del 22 de junio de 2007, debe publicar dichas resoluciones; sin embargo, creemos que como una medida de protección al derecho de la privacidad de los consumidores en general, se debe omitir la razón social y solamente relacionar las resoluciones con los números de identificación del servicio (NIS). Además es indispensable que se elimine el arto. 5 de la Ley No. 554, Ley de Estabilidad Energética, puesto que éste es contrario al Principio de Proconsumidor y correctivo que establece la Ley No. 842 (20I3) y además constituye un mecanismo abusivo de cobranza.

6. Respecto a que los derechos de los consumidores, son reconocidos como derechos humanos de tercera generación por la Organización de Naciones Unidas y tomando en cuenta que Nicaragua es miembro integrante de la misma, consideramos que con el objeto de promover políticas de protección de los consumidores, y en vista que el Instituto Nicaragüense de Energía goza de autonomía orgánica, se debería reestructurar la organización orgánica del ente regulador, creando una Dirección General de Protección a las Personas Consumidoras y Usuarias, la cual debe tener las funciones de asesorar, tramitar quejas, promover campañas de capacitación sobre los derechos de los consumidores y sobre todo velar por los derechos contenidos en la Ley No. 842 (20|3).

7. En el estudio realizado de derecho comparado con los sistemas de España y 
Argentina pudimos concluir que determinar un órgano especializado para la regulación de las relaciones de consumo de energía eléctrica, es una buena práctica, ya que con ello se asegura una verificación técnica de calidad, puesto que por lo general se cuenta con aparatos especializados para determinar la precisión de los equipos de medición, lo que promueve soluciones verdaderas a problemas técnicos de los consumidores.

\section{Lista de referencias}

Acedo. P. A. (2009). Derecho del Consumidor: Nociones de Derecho de Consumo, Aspectos de la Protección Jurídica de los Consumidores. Recuperado el día 15 de marzo de $2016 \mathrm{de}$, http://virtual.uca.edu.ni/mod/folder/view.php?id=189807

Acuerdo INE-03-I I-2005, Normativa Gran Consumidor. Publicado en La Gaceta, Diario Oficial No. 236 , el 06 de diciembre de 2005. Nicaragua.

Alave. A. B. (20I3). El derecho del consumidor y la protección de los datos personales. Recuperado el día 24 de mayo de 2015, de http://oiprodat.com/2013/03//4/elderecho-del-consumidor-y-la-proteccion-de-datos-personales/

Anónimo. (s.f). La Energía Eléctrica como un Derecho Humano. La Verdad del Sureste. Recuperado el día 26 de abril de 2016 de, http://www.la-verdad.com.mx/energiaelectrica-como-derecho-humano-50454.html

Anónimo. (2005, 31 de mayo). Nicaragua, en crisis energética. El Diario de Hoy. El Salvador. Recuperado el día 28 de abril de 2016, de http://archivo.elsalvador.com/noticias/2005/05/3I/negocios/neg5.asp

Anónimo. (2013, 12 de febrero). TSK Melfosur compra a Union Fenosa. Hoy. Recuperado el día 23 de abril de 2016 de http://www.hoy.com.ni/2013/02/I2/tskmelfosur-compra-a-fenosal

Anónimo. (2013, 05 de septiembre). ¿Qué es la CNMC? El Mundo. Recuperado el día 3I de mayo de 2016 de http://www.elmundo.es/elmundo/2013/09/05/economia//378377554.html

Anónimo. (2016, 17 de enero). Cambio de la matriz energética y electrificación en todo el país: Empresa Nacional de Electricidad (ENEL). La voz del Sandinismo. Managua. Recuperado el 29 de abril de 2016 de http://www.lavozdelsandinismo.com/nicaragua/2016-01-17/plan-del-buengobierno-2016-cambio-de-la-matriz-energetica-y-electrificacion-en-todo-el-pais/

Asamblea Nacional. (2007). Ley No. 62I, Ley de Acceso a la Información Pública, publicada en La Gaceta, Diario Oficial No. 1 I 8 del 22 de junio de 2007. Nicaragua.

Asamblea Nacional. (20I2). Ley No. 272, Ley de Industria Eléctrica, publicada en La Gaceta, Diario Oficial No. 172 del 12 de septiembre de 2012. Nicaragua.

Asamblea Nacional. (2012). Ley No. 554, Ley de Estabilidad Energética, publicada en La Gaceta, Diario Oficial No. 175 del 13 de septiembre de 2012. Nicaragua.

Asamblea Nacional. (2012). Ley No. 66I, Ley para la Distribución y el Uso Responsable del Servicio Público de Energía Eléctrica, publicada en La Gaceta, Diario Oficial No. 175 del 13 de septiembre de 2012. Nicaragua. 
Asamblea Nacional. (20I2). Ley No. 787, Ley de Protección de Datos Personales, publicada en La Gaceta, Diario Oficial No. 6I del 29 de marzo de 2012. Nicaragua.

Asamblea Nacional. (20/3). Ley No. 290, Ley de Organización, Competencia y Procedimientos. del Poder Ejecutivo, publicada en La Gaceta, Diario Oficial No. 35 del 13 de febrero de 2013. Nicaragua

Asamblea Nacional. (2013). Ley No. 842, Ley de Protección de los Derechos de las Personas Consumidoras y Usuarias, publicada en La Gaceta, Diario Oficial No. I 29 del II de julio de 20 I3. Nicaragua.

Asamblea Nacional. (20I4). Constitución Política de la República de Nicaragua con sus reformas incorporadas, Publicado en La Gaceta, Diario Oficial No. 32 del 18 de febrero de 2014. Nicaragua.

Auping. J., De la Torre. R., Guevara. A., Llamas. I., Muñoz, C., Solís. R., et al. (2004) El análisis económico de los derecho humanos. Recuperado el día 21 de mayo de 2016, https://books.google.com.ni/books?id=wZxaG8BRbosC\&pg=PA37\&lpg=PA37\&d $q=$ Auping+un+bien+no+exclusivo $+y+$ no+excluyente\&source=b|\&ots=GP0||2Bx IW\&sig=8zhWPoK4xG3E-

8du2RmWuoghqYw\&hl=es\&sa=X\&ved=0ahUKEwifjbqh_e7MAhVG9|MKHRMp DUwQ6AEIITAB\#v=onepage\&q=Auping\%20un\%20bien\%20no\%20exclusivo\%20 $\mathrm{y} \% 20$ no\%20 excluyente $\& \mathrm{f}=$ false

Cancilleria Colombiana. (s.f.). Sistema de Integración Centroamericano. SICA. Recuperado el día 24 de abril de 2016, de http://www.cancilleria.gov.co/international/consensus/sica

Castro. J. R \& Valverde L.A. (20I2). Derechos del Consumidor como Derecho Humano de Tercera Generación, su protección y defensa en la Legislación Contenciosa Administrativa Costarricense. (Tesis inédita de grado obtenido). Universidad de Costa Rica, San José, Costa Rica.

Comisión Económica para América Latina y el Caribe. (2003). Evaluación de Diez Años de Reforma de la Industria Eléctrica en el Istmo Centroamericano. Condiciones Generales de los países al inicio de las Reformas de la Industria Eléctrica. Recuperado el día 28 de abril de 2016, de http://repositorio.cepal.org/bitstream/handle/I I362/257/9/I/LCMEXL588_es.pd $\underline{f}$

Damianovich. A. (s.f.). Derecho Público: Servicio Eléctrico. Recuperado el día 23 de abril de 2016,

de

http://www.labibliotecadelabogado.com/biblioteca_ver/24/3/22/derechopublico/servicio-electrico/

Decreto No. 87. (20/2). Ley Orgánica del Instituto Nicaraguense de Energía (INE), publicada en La Gaceta, Diario Oficial No. 172 del 10 de septiembre de 2012. Nicaragua.

Decreto No. 36-20I3. (2013). Reglamento de la Ley No. 842, Ley de Protecciòn de los Derechos de las Personas Consumidores y Usuarias. Publicado en La Gaceta, Diario Oficial No. 192, del 10 de octubre de 2013. Nicaragua. 
Durban. R. (2008). Energía y Regulación en Iberoamérica. La Consideración del Consumidor. Derechos y Sistemas de Protección. Pamplona España. Vol.I

Escobar. M. K., \& Arguello. M. G. (20I5). El Hurto de Energía Eléctrica en el Ecuador: Un análisis constitucional del servicio público de electricidad y su problemática respecto a su tipificación. Recuperado el día 27 de abril de 2016, de http://www.sectorelectricidad.com/I3394/el-hurto-de-energia-electrica-en-elecuador-un-analisis/

Escobar. M. (20I5, 24 de abril). Consumidor Financiero. El Nuevo Diario. Recuperado el día 03 de julio de 2016 de, http://www.elnuevodiario.com.ni/economia/3584I2-consumidor-financiero/

Empresa Nacional de Transmisión Eléctrica. (s.f.) Antecedentes. Recuperado el día 17 de abril de 2016 de, http://www.enatrel.gob.ni/index.php/telecomunicaciones/35red-fibra-optica/39-antecedentes

Fandiño. E. (2008). Energía y Regulación en Iberoamérica. Regulación y Funcionamiento del Sector Eléctrico en Argentina. Pamplona España. Vol. 2.

Fundación ETEA. (s.f). Integración Centroamericana. Recuperado el día 27 de abril de 2016 ,

de,

http://comunidadcentroamericana.fundacionetea.org/index.php/integracioncentroamericana

Grigsby. W. V. (20I0). La aventura de producir energía azul en el Caribe. Revista Envío. Recuperado el día 28 de abril de 2016 de, www.envio.org.ni/articulo/4277

Instituto Nicaragüense de Energía. (s.f.) Marco Institucional. Recuperado el día 18 de abril de 2016 de, http://www.ine.gob.ni/marcolnstitucional.html

Instituto Nicaragüense de Energía. Normativa de Servicio Eléctrico, aprobada el día 17 de julio de $200 \mathrm{I}$.

Lifschitz. R. \& Valenzuela. P.A. (20I2). El sistema de integración Centroamericano frente a amenazas emergentes no militares. El crimen organizado, la pobreza y las necesidades energéticas. Paper. Recuperado el día 25 de abril de 2016, de http://www.academia.edu/I52625I/El_sistema_de_integraci\%C3\%B3n_centroa mericano frente a amenazas emergentes no militares_El_crimen_organizad o la pobreza y las necesidades energ\%C3\%A9ticas

Ministerio de Energía y Minas. (20I4). Manual de Organización y Funciones. Managua. Recuperado el día 27 de abril de 2016, de http://www.mem.gob.ni/media/file/INSTITUCION/MOF\%2020I4.pdf

Ministerio de Energía y Minas. (2013). El Mercado Eléctrico de Nicaragua. Managua. Recuperado el día 27 de abril de 2016 de, http://www.mem.gob.ni/media/file/ELECTRICIDAD/Descripcion\%20General\%20 del\%20MEN\%20Enero2013.pdf

Plan Nacional de Desarrollo Humano. (2012). Política de Infraestructura energética. Recuperado el día 07 de mayo de 2016 de http://www.pndh.gob.ni/documentos/pndhActualizado/pndh.pdf

Prado. R. Y. (2016, II de febrero). Junta Directiva del SIEPAC sostiene reunión bimensual en Nicaragua. El 19 Digital. Recuperado el día 25 de abril de 2016 de http://www.ell 9digital.com/articulos/ver/titulo:38765-junta-directiva-del-siepacsostiene-reunion-bimensual-en-nicaragua 
ProNicaragua. (20I4). Más Energía Renovable en la matriz energética de Nicaragua. Managua. Recuperado el 29 de abril de 2016, de www.pronicaragua.org/es/salade-prensa/969-mas-energia-renovable-en-la-matriz-energetica-de-nicaragua

Quezada. S. (20I5). Sistema de Interconexión Eléctrica de los países de América Central: Proyecto Mesoamérica. Revista Enfoque Jurídico. Recuperado el día 27 de abril de 2016 de http://www.enfoquejuridico.info/wp/archivos/2696 